\title{
Ply durations in a multiple punishment schedule'
}

DIANE D. EDWARDS AND GAIL A. DART

UNIVERSITY OF MISSOURI AT KANSAS CITY

A parametric experiment was performed to test how long behavioral deceleration could be maintained in one ply of a multiple punishment schedule. The results indicated that the duration of plys could be increased up to alternate days of two hour sessions before complete recovery of pre-punishment rates occurred. Functional differences between punishment programmed alone and in a multiple schedule were systematically replicated.

When differential punishment contingencies are programmed in a multiple schedule, different effects occur as compared to each contingency alone (DeArmond, 1966). More specifically, when punishment of each response is programmed as one ply of a multiple fixed-ratio schedule and punishment of the first response of each ratio in the other ply, complete suppression of responding occurs in the ply where continuous punishment is delivered. In the data reported by DeArmond (1966) the plys of the multiple schedule alternated every $2 \mathrm{~min}$. The present study assessed the degree of behavioral suppression as a function of increased durations in the alternating plys of a multiple punishment schedule.

\section{Method}

Three White Carneaux pigeons were used as Ss. Each was maintained at $80 \%$ of its ad lib feeding weight. Each had an experimental history of fixed-ratio reinforcement and punishment schedules similar to those of the present study.

The experimental chamber was a Lehigh Valley 1519C pigeon chamber. Mixed grain served as the reinforcer throughout the experiment and was presented for a constant duration per reinforcer. House-light and key light illumination were present except for the period of time during which reinforcers were available. A relay click provided response feedback following each peck of the response key.

Punishment was a 60 cycle ac shock delivered through $10,000 \mathrm{ohms}$ in series with the bird. Using a procedure developed by Azrin (1959), the shock was delivered through electrodes implanted around the pubis bone of the pigeon. Intensity of the shock was regulated by a variac and measured by means of a voltmeter. All electrical manipulations were designed by Lehigh Valley and Grason-Stadler Electronics Companies.

A multi-element baseline of responding was established using a variable-interval schedule of $2 \mathrm{~min}$. A reinforcer was delivered on the average of every 2 min. During baseline conditions, red and green key lights were alternated every $15 \mathrm{~min}$. Each experimental session was $2 \mathrm{hr}$. in length. Baseline conditions were maintained until a stability criterion of not more than $5 \%$ deviation in rate of response over six consecutive days was met (Sidman, 1960).

When stable baseline responding had been established, two punishment contingencies were introduced, one under each ply of the multiple schedule. The different key colors now served as discriminative stimuli for the punishment contingency present in each ply. Continuous punishment (shock contingent on each response) was introduced in one ply while in the other a shock was made contingent only on the first response after each reinforcer was delivered. The continuous punishment contingency was introduced in the ply in which baseline rates were highest for each $\mathrm{S}$. Consequently for one $S$ it was red while for another it could be green. The variable interval programmer was set to give a shock-free reinforcer for the first response of each session. Shock intensity was raised in each session from $20 \mathrm{v}$, in $10-$ and $20-\mathrm{v}$ increments, until nearly complete suppression had occurred in the continuous punishment condition. This required an intensity of $60 \mathrm{v}$ for $\mathrm{P}-90$ and $\mathrm{P}-71$ and $70 \mathrm{v}$ for $\mathrm{P}-73$. The duration of the shock was held constant at $50 \mathrm{msec}$.

At this point in the experiment the duration manipulations were made. Increase in the duration of each alternated punishment condition were made in the following steps: $15 \mathrm{~min} ., 1 / 2 \mathrm{hr}, 1 \mathrm{hr}, 2 \mathrm{hr}$., and two full sessions. The intensity and duration of shock were held constant throughout the increasing ply durations.

\section{Results}

Figure 1 presents the progressive development of ply-duration manipulations in two of the three Ss. By the thirteenth session, responding had decelerated in the continuous punishment ply and responding in the first response following reinforcement ply had accelerated above baseline rates for both $\mathrm{P}-90$ and $\mathrm{P}-71$.

During the maintenance of the $15-$ min. alternation of each ply of the multiple schedule, differential responding continued. Complete behavioral suppression was maintained by $P-71$ during the continuous punishment ply while P-90's rate fluctuated between 0 and 10 responses per min.

When the ply durations were increased to $30-\mathrm{min}$. alternations, P-71 showed no recovery of responding in the continuous punishment ply. However, P 90's rate began to accelerate so that by session 32 , the rate was fluctuating between 20 and 40 responses per min. Increasing the ply durations to $60 \mathrm{~min}$. alternations did not change the differential responding from that obtained from $30 \mathrm{~min}$. alternations. 


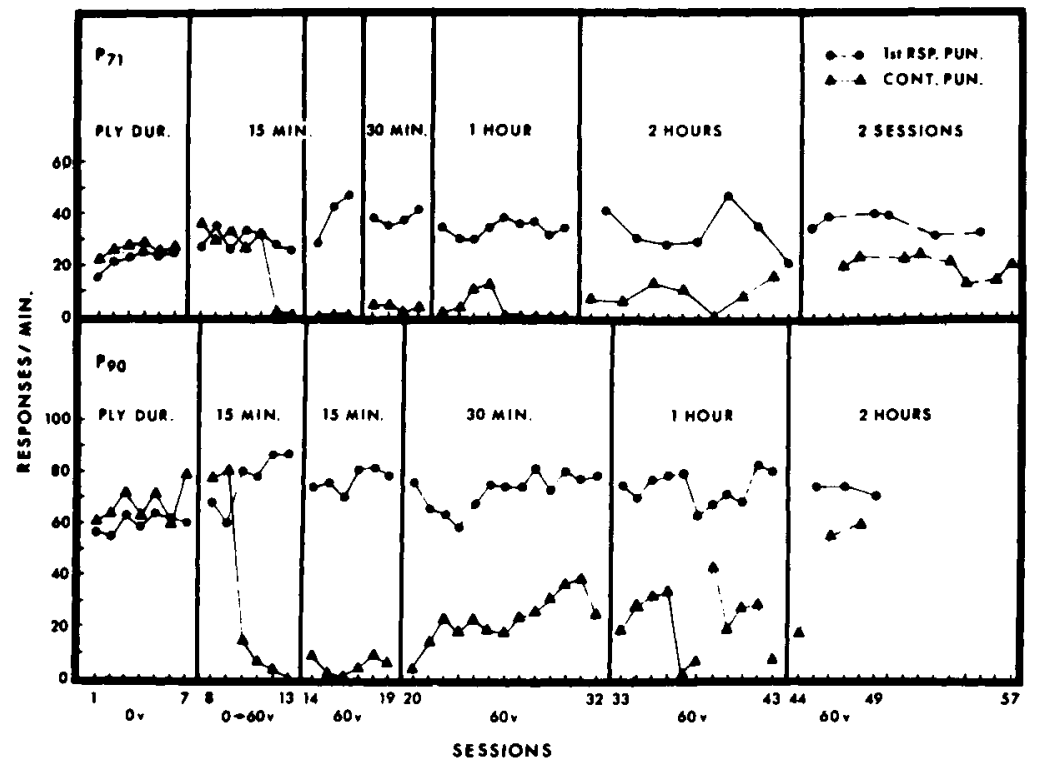

Fig. 1. Progressive development of behavioral effects of ply duration increase for P-71 and P90 .
When the ply durations were increased to $2 \mathrm{hr}$., each $\mathrm{S}$ was now exposed to complete sessions of continuous punishment alternated with complete sessions of punishment of the first response following reinforcement. P-90 showed recovery of baseline rates during this manipulation, but $\mathrm{P}-71$ 's rate showed acceleration only to 15 responses per min.

Since P-71's rate had not yet recovered to baseline rates, another manipulation was made by increasing the ply durations to two full consecutive sessions. During this manipulation, the rate in the continuous punishment ply recovered to the baseline rate. However, for both $\mathrm{P}-71$ and $\mathrm{P}-90$ the rate in the continuous punishment ply never reached the accelerated rate in the first response ply. Once the punishment contingencies were introduced, responding in the first response ply accelerated over baseline rates and were maintained during all ply duration manipulations.

\section{Discussion}

The effect of punishing each response in variable interval behavior has been reported by Azrin (1960a,b) to be a general reduction in responding. When continuous punishment is programmed as one ply of a multiple punishment schedule, the behavioral effects are not characteristic of behavior when it is programmed alone. In fact, the data from the present study demonstrate that behavior punished under multiple schedule will be completely suppressed as compared to behavior punished continuously on a straight variable interval schedule. These behavioral effects are extremely sens. ive to the duration of each ply of the multiple schedule since as the duration increases, behavioral deceleratic 1 decreases.

Using a mild punishment with human Ss, suppression of the punished response was possible only after an alternative response was made available (Holz, Azrin, \& Ayllon, 1963; Herman \& Azrin, 1964). These authors concluded that mild punishment is ineffective in reducing the frequency of responding if the punished response constitutes the only means of obtaining a reinforcer. They also suggested that the most expedient method of suppressing a response would be to provide an alternative way of producing reinforcers while punishing the undesired response.

The general effect of increasing duration of the two plys in the multiple schedule seemed to be a lessening of the strength of the alternative response. The results indicated that the more remote in time the alternative, the less control it exerts over the behavior during continuous punishment.

\section{References}

Azrin, N. H. A technique for delivering shock to pigeons. $J$. exp. Anal. Behav., 1959, 2, 161-163.

Azrin, N. H. Sequential effects of punishment. Science, 1960a, $131,605-606$.

Azrin, N. H. Effects of punishment intensity during variable-interval reinforcement. J. exp. Anal. Behav., 1960b, 3, 123-142. DeArmond, D. Multiple Punishment Schedule. J. exp. Anal. Behav., $1966,9,327-334$.

Herman, R. L., \& Azrin, N. H. Punishment by noise in an alternative response situation. J. exp. Anal. Behav., 1964, 7, 185-188.

Holz, W. C., Azrin, N. H., \& Ayllon, T. Elimination of behavior of mental patients by response-produced extinction. J. exp. Anal. Behav., 1963, 6, 407-412.

Sidman, M. Tactics of Scientific Research. New York: Basic Books, Inc., 1960.

\section{Notes}

1. This research was supported by Grant MH-11205-01 1rom the National Institute of Mental Health, U. S. Public Health Service to the first author. 